Relations industrielles

Industrial Relations

\title{
Index de la première série de Bulletins des relations industrielles
}

Volume 1, numéro 10, juin 1946

URI : https://id.erudit.org/iderudit/1023962ar

DOI : https://doi.org/10.7202/1023962ar

Aller au sommaire du numéro

Éditeur(s)

Département des relations industrielles de l'Université Laval

ISSN

0034-379X (imprimé)

1703-8138 (numérique)

Découvrir la revue

Citer cet article

(1946). Index de la première série de Bulletins des relations industrielles.

Relations industrielles / Industrial Relations, 1(10), 8-8.

https://doi.org/10.7202/1023962ar

Tous droits réservés @ Département des relations industrielles de l’Université Laval, 1946
Ce document est protégé par la loi sur le droit d'auteur. L'utilisation des services d'Érudit (y compris la reproduction) est assujettie à sa politique d'utilisation que vous pouvez consulter en ligne.

https://apropos.erudit.org/fr/usagers/politique-dutilisation/ 


\section{INDEX DE LA PREMIÈRE SÉRIE}

DE

\section{BULLETINS DES RELATIONS INDUSTRIELLES}

\section{Septembre 1945}

Le Département des Relations industrielles de la Faculté des Sciences sociales.

L'avenir de l'organisation internationale du travail.

Clauses d'arbitrage dans les conventions collectives.

Les centres d'apprentissage.

Lois nouvelles de la Législature provinciale - 1945 .

Le gouvernement fédéral et les problèmes du travail.

\section{Octobre 1945}

La noblesse du travail.

L'aspect légal du salaire dans le Québec.

Les commissions d'industrie.

Sécurité syndicale.

Nécessité des associations patronales.

Le service provincial de placement.

"Union Security Plans " (Recension).

\section{Novembre 1945}

Crise de confiance.

Clauses de retenue des cotisations syndicales.

Les comités d'entreprise en France.

Réadaptation au travail.

Syndicalisme et action politique.

( Essential Elements of Trade Union Agreements.)

Pratiques interdites aux employeurs et aux associations ouvrières.

\section{Décembre 1945}

Loyauté et discipline.

Clauses de maintien d'affiliation syndicale.

La santé industrielle.

Le Conseil supérieur du travail.

Pas de grève de sympathie.

Structure du ministere provincial du travail.

Progrès de l'organisation professionnelle.

"Handhing Shop Grievances."

\section{Janvier 1946}

Les contremaîtres et la convention collective.

Clauses d'atelier syndical et d'atelier fermé.

La santé de l'ouvrier, facteur d'économie.

L'extension juridique.

Comparaison des salaires et des heures de travail entre

le Canada et les Etats-Unis.

\section{Février 1946}

Facteurs nouveaux dans l'aménagement des relations du travail.

Conflits et arbitrage.

Un code provincial du travail.
" Some conclusions Regarding Union-Management Relations.)"

Congrès des relations industrielles de Laval.

\section{Mars 1946}

Lendemain de congrès.

L'atelier préférentiel.

La sécurité industrielle (I).

Les relations industrielles dans l'Etat moderne.

L'Université et les relations industrielles.

\section{Avril 1946}

L'ouvrier et son syndicat.

- Esquisses psychologiques - L'employeur (I).

Session intensive en relations industrielles.

Amendements à notre législation ouvrière.

La sécurité industrielle (II).

\section{Mai 1946}

Gare à la tactique communiste.

Esquisses psychologiques - L'employeur (II).

Un département de physiologie du travail.

" Building Employee Security - What the Supervisor

Can Do.")

Les congés payés dans la province de Québec.

Double caractère du travail.

Productivité du travail, source de richesses.

(The Qualified Wage Negotiator.»

\section{Juin 1946}

L'infiltration communiste.

Vouloir et savoir négocier.

Esquisses psychologiques - L'ouvrier.

"The Will and the Way to Negotiate."

Mémoires et thèses sur les relations industrielles.

\section{JOURNÉES INDUSTRIELLES}

Nous avons le plaisir d'annoncer que le Département des Relations industrielles de la Faculté des Sciences sociales de Laval est à organiser, pour les 16, 17, 18 et 19 juin prochains, une première série de journées industrielles, dans le diocèse de Rimouski. Employeurs et travailleurs sont invités à suivre les cours et à participer aux forums qui porteront principalement sur la convention collective, la conciliation et l'arbitrage.

Les cours se donneront aux endroits suivants : Price, Matane, Rimouski et Cabano. 